\title{
ФУНДАМЕНТАЛЬНЫЙ ХАРАКТЕР ПРИНЦИПОВ ГРАЖДАНСКОГО ПРАВА И ДОПУСТИМЫЕ ПРЕДЕЛЫ ИХ ОГРАНИЧЕНИЯ (НА МАТЕРИАЛАХ РОССИИ И БЕЛАРУСИ)
}

\begin{abstract}
Аннотация: Впервые за всю историю отечественного гражданского права принципы текстуально закреплены 6 гражданском законодательстве с приданием им статуса его основных начал. Законодательное признание приниипов гражданского права, с одной стороны, стало отправной точкой становления национального гражданского законодательства России и Беларуси, а, с другой-актуализировало проблему его формирования в соответствии с продекларированными основными началами, важной составляющей которой является решение вопроса о допустимости ограничений принципов как фундаментальных положений законодательства. На основе анализа законодательства России и Беларуси, а также положений правовой доктрины, авторы статьи предпринимают попытку определить допустимые предель ограничения основных начал гражданского законодательства, а также вносят ряд предложений по совершенствованию законодательства с учетом требований его основных начал. Выдвигается тезис о том, что принятию решения о введении тех или иных ограничений принципов гражданского права, должна предшествовать оценка их оправданности с точки зрения баланса частных и общественных интересов. Законодателю надлежит неукоснительно следовать правилу в соответствии с которым любое ограничение принципа должно устанавливаться только на основании закона и в соответствии с Конституцией страны.

Abstract: For the first time in the history of Russian civil law, civil law principles have been enshrined verbatim in legislation, giving them 'first principle' status. On the one hand, legislative recognition of the principles of civil law has become the starting point for the development of national civil law legislation of Russia and Belarus. Conversely, it has brought to the fore the problems of such development in accordance with the declared first principles, an important component of which is the question of the acceptability of restrictions on principles as fundamental provisions of the legislation. Based on an analysis of the legislation of Russia and Belarus, as well as statements of legal doctrine, the authors attempt to define acceptable limits on the restrictions of the first principles of civil law, as well as make a number of suggestions to improve the legislation to meet the first-principle requirements. They argue that the decision to introduce restrictions of the principles of civil law must be preceded by an assessment of their justification in terms of the balance between private and public interests. It behoves legislators to strictly follow the rule that any restriction of a legal principle should be created only according to law and in accordance with the Constitution.
\end{abstract}

Ключевые слова: гражданское право, гражданское законодательство, ограничение принципов, правовая норма, приниипы права, гражданские права, правовая система, защита прав человека, общественные интересы, ограничение прав Keywords: civil law, civil law legislation, restrictions on principles, rule of law, principles of law, civil rights, legal system, protection of human rights, public interest, restriction of rights

советской цивилистической доктрине традиционно господствовавшим являлся взгляд на правовые принципы как на фундаментальные положения, в которых отражаются основные свойства, специфические качества права, проявляется его сущность $^{1}$. Сегодня вывод о фундаментальном характере гражданско-правовых принципов основан не только на теоретических исследованиях ученых, но и вытекает из действующего законодательства. В Гражданском

\footnotetext{
${ }^{1}$ Алексеев С.С. Проблемы теории права: курс лекций: в 2 т. Свердловск, 1972. Т. 1, С. 10
}

кодексе Российской федерации (далее - ГК России) и в Гражданском кодексе Республики Беларусь (далее ГК Беларуси) содержатся статьи, которые называются «Основные начала гражданского законодательства» и закрепляют систему гражданско-правовых принципов в качестве таковых (ст. 1 ГК России; ст. 2 ГК Беларуси $)^{23}$. То обстоятельство, что принципам придан

\footnotetext{
${ }^{2}$ Гражданский кодекс Российской Федерации // КонсультантПлюс http://www.consultant.ru/law/doc/gk/

${ }^{3}$ Гражданский кодекс Республики Беларусь: Принят Палатой представителей 28 окт. 1998г.: Одобрен Советом Респ. 19 нояб. 1998г.: Офиц. изд. - Минск: НЦПИ, 1999. - 511 с.
} 
DOI: 10.7256/1811-9018.2013.11.10033

При цитировании этой статьи сноска на dоі обязательна

Человек и государство

статус основных начал гражданского законодательства, означает, что они обладают большей нормативностью, устойчивостью и стабильностью по отношению к иным юридическим нормам.

Однако, как убедительно свидетельствует правоприменительная практика, законодательное закрепление правового принципа не является безусловным свидетельством его окончательного перехода в практическую плоскость. К сожалению, все еще нередки случаи, когда в процессе разработки конкретных нормативных правовых актов требования принципов законодателем не учитываются, в результате чего правовые нормы противоречат требованиям основных начал. Между тем, как весьма точно заметил Р.3. Лившиц, «правовые принципы только в том случае имеют юридическую ценность, если они будут реализовываться через конкретные правовые нормы конкретных отраслей права 4 . Мы разделяем мнение ученых, которые полагают, что руководство требованиями принципов, их учет в процессе правотворческой деятельности придадут концептуальный характер гражданскому законодательству, обеспечат системность и единство гражданско-правовых норм, что в свою очередь, будет способствовать повышению эффективности гражданско-правового регулирования ${ }^{5678}$.

Если исходить из справедливого утверждения о том, что «принципы выступают в качестве своеобразной несущей конструкции, на основе которой создаются и реализуются не только нормы, институты и отрасли, но и вся система права» ${ }^{9}$, то постоянное ограничение требований принципов следует рассматривать в качестве угрозы стабильности правовой системы. Возникает закономерный вопрос: «Как разрешить противоречие между фундаментальным характером правовых принципов и возможностью их ограничения, и где находятся допустимые пределы таких ограничений?»

\footnotetext{
${ }^{4}$ Лившии Р.3. Современная теория права: крат. очерк; Рос. акад. наук, Ин-т государства и права. - М., 1992, С. 195.

${ }^{5}$ Комиссарова Е. Г. Об основных началах гражданского законодательства С. 13-20 // Журнал российского права. 2001. № 5. С. 13.

${ }^{6}$ Кузнецова О.А. Общепризнанные принципы и нормы международного права - часть правовой системы, права или законодательства? // Правовое государство: теория и практика. 2010. № 2. С. 42.

${ }^{7}$ Кузнецова О.А. Принципы гражданского права: современное состояние вопроса // Власть закона. 2011. № 4 (8). С. 87.

${ }^{8}$ Martijn W. Hesselink The general principles of civil law: their nature? Roles and legitimacy Режим доступа:// http://ssrn.com/ abstract $=1932146$

${ }^{9}$ Матузов Н.И. Теория государства и права: учебник - М.: Юристъ,
} 2003, С. 164.
В международно-правовых актах в сфере защиты прав человека, а также в Конституции определены допустимые пределы ограничения принципов права. Так, в ст. 29 Всеобщей декларации прав человека установлено, что при осуществлении своих прав человек должен подвергаться только таким ограничениям, какие установлены законом исключительно с целью обеспечения должного признания и уважения прав и свобод других и удовлетворения справедливых требований морали, общественного порядка и общего благосостояния в демократическом обществе ${ }^{10}$. В соответствии с Конституцией Российской федерации права и свободы человека и гражданина могут быть ограничены федеральным законом только в той мере, в какой это необходимо в целях защиты основ конституционного строя, нравственности, здоровья, прав и законных интересов других лиц, обеспечения обороны страны и безопасности государства $(\text { ст. } 55)^{11}$. Аналогичное положение закреплено и в ст. 23 Конституции Республики Беларусь ${ }^{12}$.

В гражданском законодательстве названный конституционно-правовой принцип реализуется через закрепленный в числе основных начал гражданского законодательства принцип недопустимости произвольного вмешательства в частные дела: «Гражданские права могут быть ограничены на основании федерального закона и только в той мере, в какой это необходимо в целях защиты основ конституционного строя, нравственности, здоровья, прав и законных интересов других лиц, обеспечения обороны страны и безопасности государства» (ст. 1 ГК России). Согласно ст. 2 ГК Беларуси вмешательство в частные дела не допускается, за исключением случаев, когда такое вмешательство осуществляется на основании правовых норм в интересах национальной безопасности, общественного порядка, защиты нравственности, здоровья населения, прав и свобод других лиц. Нетрудно заметить, что термин «закон» заменен термином «правовая норма», что вызывает несогласие, поскольку как справедливо отмечает В.Ф. Яковлев, любое, не основанное на законе вмешательство в частные дела, является произвольным. Для допущения вмешательства нужно, чтобы оно было прямо предусмотрено законом в виде определенных

\footnotetext{
${ }^{10}$ Всеобщая декларация прав человека: полн. текст: утв. и провозглашена Генер. Ассамблеей Орг. Объед. Наций 10 дек. 1948 г. - М., 1996.

${ }^{11}$ Конституция Российской федерации. Режим доступа: // http://constitution.ru/

${ }^{12}$ Конституция Республики Беларусь 1994 года (с изменениями и дополнениями, принятыми на республиканских референдумах 24 ноября 1996 г. и 17 октября 2004 г.). - Минск, 2005.
} 
DOI: $10.7256 / 1811-9018.2013 .11 .10033$

При цитировании этой статьи сноска на dоі обязательна

\section{Право и политика $11(166) \cdot 2013$}

законом полномочий того или иного государственного органа или представителя власти» ${ }^{13}$. Формируя нормы отраслевого законодательства, законодатель не должен отступать от конституционных принципов. На необходимость постоянного учета феномена одновременного участия норм конституционного и отраслевого права в механизме правового регулирования общественных отношений обращает внимание и Г.А. Гаджиев, отмечая, что нормы гражданского законодательства регулируют общественные отношения под бдительным контролем конституционных норм и принципов» ${ }^{14}$.

Принцип недопустимости произвольного вмешательства в частные дела, с одной стороны, адресован публичной власти, которая должна воздерживаться от вмешательства в частные дела субъектов гражданских правоотношений, а с другой стороны - участникам гражданских правоотношений, которые обязываются воздерживаться от незаконного вмешательства в дела друг друга. Принцип недопустимости произвольного вмешательства в частные дела предполагает недопустимость вмешательства в сферу правомерной предпринимательской деятельности физического или юридического лица. В тех случаях, когда вмешательство в частные дела объективно необходимо, оно должно осуществляться в порядке и на условиях, предусмотренных в законе при наличии действительно веских оснований. Так, законом может быть закреплено исключительное право государства на осуществление отдельных видов деятельности, для ведения некоторых видов предпринимательской деятельности необходимо специальное разрешение (лицензия) компетентного государственного органа, которому предоставлено право отказать в выдаче такого разрешения, если заявитель не удовлетворяет установленным требованиям. В некоторых случаях законодатель считает необходимым вмешаться в сферу частных отношений с целью защиты интересов отдельных участников гражданского оборота, либо для ограничения и пресечения монополистической деятельности и недобросовестной конкуренции. Такие ограничительные правила устанавливаются на основании закона, отвечают интересам общества, следовательно, не выходят за пределы допустимых ограничений исследуемого принципа.

\footnotetext{
${ }^{13}$ Гражданское право: учебник / О.В. Бойков [и др.]; под общ. ред. В.Ф. Яковлева; Рос. акад. гос. службы при Президенте Рос. Федерации. - М., 2003, С. 23.

${ }^{14}$ Гаджиев Г.А. Конституционные принципы рыночной экономики: развитие основ гражданского права в решениях Конституционного Суда Российской Федерации - М., 2002, С. 17.
}

Однако в действующем законодательстве мы обнаруживаем примеры, которые свидетельствуют о неоправданном ограничении принципа недопустимости произвольного вмешательства в частные дела. Так, в п. 2 ст. 392 ГК Беларуси «Договор и законодательство» закреплено: «Если после заключения и до прекращения действия договора принят акт законодательства, устанавливающий обязательные для сторон правила, иные, чем те, которые действовали при заключении договора, условия заключенного договора должны быть приведены в соответствие с законодательством, если иное не предусмотрено законодательством». При этом перечень актов законодательства Беларуси весьма значителен. Наряду с законами, декретами, указами и распоряжениями Президента Республики Беларусь, в него включены также постановления Правительства Республики Беларусь, акты Конституционного Суда Республики Беларусь, Верховного Суда Республики Беларусь, Высшего Хозяйственного Суда Республики Беларусь, а также другие акты законодательства по регулированию гражданских отношений (ст. 3 ГК Беларуси). Таким образом, на законодательном уровне закрепляется приоритет законодательства над договором, устанавливается порядок, при котором правовая норма любого нормативного акта может ограничивать действие основного начала гражданского законодательства. Полагаем, что формулировка п. 2 ст. 422 ГК России «Договор и закон» в большей мере соответствует требованиям исследуемого принципа: «Если после заключения договора принят закон, устанавливающий обязательные для сторон правила иные, чем те, которые действовали при заключении договора, условия заключенного договора сохраняют силу, кроме случаев, когда в законе установлено, что его действие распространяется на отношения, возникшие из ранее заключенных договоров».

Закрепленный в числе основных начал гражданского законодательства принцип равенства участников гражданских правоотношений имеет целью недопущение предоставления отдельным участникам гражданского оборота противоречащих закону преимуществ и привилегий. Само наличие в гражданском законодательстве преимущественных прав и привилегий не может вызывать возражений, если они предоставляются для защиты социально значимых законных интересов, для придания устойчивости гражданско-правовым отношениям, нацелены на корректировку неравенства участников гражданских правоотношений, и устанавливаются на основании закона, а не иного нормативного правового акта. Например, если речь идет о 
DOI: 10.7256/1811-9018.2013.11.10033

При цитировании этой статьи сноска на dоі обязательна

Человек и государство

предоставлении дополнительных правовых гарантий гражданам-потребителям или гражданам в их взаимоотношениях с предпринимателями. Так, в Решении Конституционного Суда Республики Беларусь «О конституционности уменьшения банками в одностороннем порядке процентных ставок по договорам банковского вклада (депозита)» от 6 ноября 2002 г. № Р-150/2002 указано, что «исходя из конституционной свободы договора, законодатель не вправе ограничиваться формальным признанием юридического равенства сторон и должен предоставлять определенные преимущества экономически слабой и зависимой стороне, с тем, чтобы не допустить недобросовестной конкуренции в сфере банковской деятельности и реально гарантировать в соответствии со статьями 13, 22 Конституции соблюдение принципа равенства при осуществлении предпринимательской и иной не запрещенной законом экономической деятельности» ${ }^{15}$.

Установлением преимущественных прав может преследоваться цель стимулирования развития предпринимательства, в частности малого и среднего бизнеca, создающего основу экономического благосостояния страны. Так, Федеральным Законом «Об особенностях отчуждения недвижимого имущества, находящегося в государственной собственности субъектов Российской федерации или в муниципальной собственности и арендуемого субъектами малого и среднего предпринимательства, и о внесении изменений в отдельные законодательные акты Российской федерации» от 22 июля 2008 г. № 159-Ф3 субъектам малого и среднего предпринимательства (за исключением названных в Законе) при возмездном отчуждении арендуемого имущества из государственной собственности субъекта Российской Федерации или муниципальной собственности предоставлено преимущественное право на приобретение такого имущества по рыночной цене ${ }^{16}$.

Вместе с тем не всегда ограничения исследуемого принципа могут быть оправданы интересами общества. Так, в соответствии с ч. 2 п. 2 Указа Президента

\footnotetext{
${ }^{15} \mathrm{O}$ конституционности уменьшения банками в одностороннем порядке процентных ставок по договорам банковского вклада (депозита): Решение Конституционного Суда Респ. Беларусь, 6 нояб. 2002 г., № Р-150/2002 // КонсультантПлюс: Беларусь. Технология ПРОФ [Электронный ресурс] / ООО «ЮрСпектр» Минск, 2013.

${ }^{16}$ Об особенностях отчуждения недвижимого имущества, находящегося в государственной собственности субъектов Российской федерации или в муниципальной собственности и арендуемого субъектами малого и среднего предпринимательства, и о внесении изменений в отдельные законодательные акты Российской федерации: Федеральный Закон от 22.07.2008 № 159-ФЗ // http://base.garant.ru/12161610/
}

Республики Беларусь от 18 июня 2005 г. № 285 «O некоторых мерах по регулированию предпринимательской деятельности», деятельность индивидуального предпринимателя в Республике Беларусь может осуществляться только с привлечением членов семьи и близких родственников (супруг (супруга), родители, дети, усыновители, усыновленные (удочеренные), родные братья и сестры, дед, бабка, внуки) ${ }^{17}$. Очевидно, что приведенная норма является дискриминационной в отношении индивидуальных предпринимателей, не имеющих членов семьи и близких родственников, в частности, сирот.

Обнаруживаются в законодательстве также ограничения принципа равенства участников гражданских правоотношений в отношениях с участием государства как особого субъекта гражданского оборота. Так, законодательством Республики Беларусь предусмотрено преимущественное право Минского горисполкома на приобретение в собственность соответствующей области, г. Минска акций (долей в уставных фондах) хозяйственных обществ с местом нахождения на территории этой области, г. Минска: включенных в перечни, утверждаемые облисполкомами, Минским горисполкомом по согласованию с Советом Министров Республики Беларусь, которые приобретены гражданами Республики Беларусь у государства за денежные средства на льготных условиях (по цене на 20 процентов ниже номинальной стоимости) и (или) в обмен на именные приватизационные чеки «Имущество», а также получены взамен долей граждан в имуществе арендных и коллективных (народных) предприятий при преобразовании их в акционерные общества; а также созданных в процессе преобразования государственных, государственных унитарных, арендных и коллективных (народных) предприятий, перерабатывающих сельскохозяйственную продукцию (п. 1.4) ${ }^{18}$. Постановлением Совета Министров Республики Беларусь от 15 августа 2013 г. № 721 утвержден перечень хозяйственных обществ, в отношении акций (долей в уставных фондах) которых Минский горисполком имеет преимущественное право на приобретение в собственность г. Минска.

\footnotetext{
${ }^{17} \mathrm{O}$ некоторых мерах по регулированию предпринимательской деятельности: Указ Президента Респ. Беларусь, 18 июня 2005 г., № 285 // КонсультантПлюс: Беларусь. Технология ПРОФ [Электронный ресурс] / ООО «ЮрСпектр». Минск, 2013.

${ }^{18} \mathrm{O}$ некоторых вопросах распоряжения имуществом, находящимся в коммунальной собственности, и приобретения имущества в собственность административно-территориальных единиц: Указ Президента Республики Беларусь, 16 нояб. 2006 г., № 677 // КонсультантПлюс: Беларусь. Технология ПРОФ [Электронный ресурс] / ООО «ЮрСпектр» Минск, 2013.
} 
DOI: $10.7256 / 1811-9018.2013 .11 .10033$

При цитировании этой статьи сноска на dоі обязательна

\section{Право и политика $11(166) \cdot 2013$}

Наряду с открытыми акционерными обществами в указанный перечень оказались включены также закрытые акционерные общества, что противоречит самой их природе, поскольку участники закрытого акционерного общества могут отчуждать принадлежащие им акции с согласия других акционеров и (или) ограниченному кругу лиц, а акционеры закрытого акционерного общества имеют преимущественное право на покупку таких акций в силу указания закона (п. 2 ст. 97 ГК Беларуси; п. 2 ст. 97 ГК России).

Принцип свободы договора по своей целевой направленности в гражданском праве призван стимулировать договорную активность субъектов гражданского оборота, предоставляя им возможность самостоятельного определения условий договора. Содержание принципа свободы договора, названного в числе основных начал гражданского законодательства как России, так и Беларуси, сводится к тому, что граждане и юридические лица свободны в заключении договора. По общему правилу, понуждение к заключению договора не допускается. Возможность установления исключения из этого правила, российский законодатель ограничивает только случаями, предусмотренными ГК России, законом или добровольно принятым обязательством. Белорусский законодатель допускает понуждение к заключению договора как на основании закона, так и другого акта гражданского законодательства (ст. 391 ГК Беларуси), что, по нашему мнению, не согласуется с фундаментальным характером принципа свободы договора как основного начала гражданского законодательства.

Важной составляющей принципа свободы договора является право субъектов гражданского оборота на самостоятельный выбор вида заключаемого договора. Статья 421 ГК России предусматривает, что стороны могут заключить договор, как предусмотренный законом, так и такой, который в законах вообще не упоминается, но будет наиболее соответствовать существу возникших между сторонами правоотношений и оптимально их регулировать. Белорусский законодатель не предоставляет субъектам договорного процесса право заключать так называемые, непоименованные (неизвестные закону, но не противоречащие общим началам и смыслу гражданского законодательства) договоры, предоставляя им лишь право заключения смешанных договоров (договоров, содержащих элементы известных законодательству договоров) (п. 2 ст. 391 ГК Беларуси). Однако такое право логично вытекает из положений ст. 7 ГК Беларуси, в соответствии с которой, гражданские права и обязанности возникают из договоров и иных сделок, предусмотренных законодательством, а также из договоров и иных сделок, хотя и не предусмотренных законодательством, но не противоречащих ему. Возможность создания новых видов договоров вытекает также из смысла п. 1 ст. 310 ГК Беларуси, закрепляющей открытый перечень способов обеспечения исполнения обязательств: «исполнение обязательств может обеспечиваться неустойкой, залогом, удержанием имущества должника, поручительством, гарантией, банковской гарантией, задатком и другими способами, предусмотренными законодательством или договором».

Фундаментальный характер принципа свободы договора не вступает в противоречие с допустимостью его ограничения. Многочисленные ограничения исследуемого принципа условно можно разделить на общие, устанавливающие общие пределы осуществления гражданских прав (ст. 9 ГК Беларуси; ст. 10 ГК России) и специальные. Так, заключение договора обязательно в случаях заключения публичного договора; заключения договора с лицом, выигравшим торги; при наличии предварительного договора и требовании его принудительного исполнения. Значительное количество оснований, свидетельствующих об обязанности заключить договор в силу требований закона, сконцентрированы в сфере страхования. Эти случаи касаются как обязательного личного, так и имущественного страхования. В частности, как в России, так и в Беларуси предусмотрено обязательное страхование гражданской ответственности владельцев транспортных средств.

Кроме того ограничения принципа свободы договора могут выражаться не только в понуждении к вступлению в договорные отношения, но и в запрете заключения договора. Так, специальный вид ограничений принципа свободы договора, выраженный в запрете на вступление в договорные правоотношения, связан с правовым регулированием монополистической деятельности.

Как в ГК России, так и в ГК Беларуси закреплен принцип неприкосновенности собственности, исходя из содержания которого собственник вправе по своему усмотрению совершать в отношении принадлежащего ему имущества любые действия, не противоречащие законодательству, общественной пользе и безопасности, не наносящие вреда окружающей среде, историко-культурным ценностям и не ущемляющие прав и защищаемых законом интересов других лиц. Собственник обладает свободой владения, пользования, распоряжения имуществом. Однако Указом Президента Республики Беларусь от 23 февраля 2012 г. № 100 «О мерах по совершенствованию учета и сокращению количества пустующих и ветхих домов в сельской местности» 
DOI: 10.7256/1811-9018.2013.11.10033

При цитировании этой статьи сноска на dоі обязательна

Человек и государство

принцип неприкосновенности собственности подвергся существенным ограничениям. В частности, право пользования имуществом трансформировалось в обязанность пользования им. Так, если в течение трех лет подряд лица, имеющие право пользования пустующими домами, проживают в них в совокупности менее одного месяца в календарном году и не представляют в исполнительный комитет первичного территориального уровня письменное уведомление о намерении использовать такой дом для проживания, их действия квалифицируются как отказ от права собственности ${ }^{19}$. Вместе с тем, в соответствии со ст. 237 ГК Беларуси отказ от права собственности осуществляется путем объявления об этом либо совершения других действий, определенно свидетельствующих об устранении собственника от владения, пользования и распоряжения имуществом без намерения сохранить какие-либо права на это имущество. Неиспользование жилого помещения для проживания не может являться безусловным свидетельством намерения лица отказаться от права собственности на жилое помещение.

Определяя содержание права собственности, законодатель устанавливает, что при осуществлении принадлежащего ему права собственности собственник не должен совершать действия, противоречащие законодательству, общественной пользе и безопасности, наносящие вред окружающей среде, историко-культурным ценностям или ущемляющие права и защищаемые законом интересы других лиц. Запреты на совершение некоторых действий могут вытекать из требований соблюдения санитарных, ветеринарных и других правил. При известных обстоятельствах закон даже санкционирует возможность принудительного изъятия у собственника имущества. Согласно ГК к числу таких оснований относятся: отчуждение имущества, которое в силу акта законодательства не может принадлежать данному лицу; отчуждение недвижимого имущества в связи с изъятием земельного участка; выкуп бесхозяйственно содержимых культурных ценностей; выкуп домашних животных; реквизиция и др. Из приведенного перечня оснований принудительного прекращения права собственности большинство носит возмездный характер и только в двух случаях речь идет о безвозмездном изъятии у собственника принад-

\footnotetext{
${ }^{19} \mathrm{O}$ некоторых мерах по совершенствованию учета и сокращению количества пустующих и ветхих домов в сельской местности: Указ Президента Республики Беларусь от 23 февр. 2012 г., № 100 // КонсультантПлюс: Беларусь. Технология ПРОФ [Электронный ресурс] / ООО «ЮрСпектр». Минск, 2013
}

лежащего ему имущества: при обращении взыскания на имущество по обязательствам и конфискации. В соответствии со ст. 243 ГК России, имущество может быть безвозмездно изъято у собственника по решению суда в виде санкции за совершение преступления или иного правонарушения (конфискация) лишь в случаях, предусмотренных законом. ГК Беларуси допускает конфискацию на основании законодательного акта (ст. 244). К числу законодательных актов относятся не только законы, но также Декреты и Указы Президента, что вступает в противоречие со ст. 44 Конституции Республики Беларусь, в соответствии с которой прекращение права собственности вопреки воле собственника должно осуществляться только в случаях, предусмотренных законом.

В соответствии с принципом добросовестности при установлении, осуществлении и защите гражданских прав и при исполнении гражданских обязанностей участники гражданских правоотношений должны действовать добросовестно. Данный принцип появился лишь в новой редакции ГК России, в ГК Беларуси названный принцип включен еще с момента принятия кодекса, однако, сформулирован в виде презумптивной нормы: добросовестность и разумность участников гражданских правоотношений предполагается, поскольку не установлено иное. Полагаем, что содержание принципа нуждается в корректировке. Несмотря на то, что презумпции и принципы права имеют много общего, принципиальная разница между ними очевидна. Она заключается в том, что презумпция - лишь вероятное предположение, которое может быть опровергнуто, в то время как принцип права представляет собой неопровержимое, основополагающее, универсальное руководящее начало, характеризующее сущность и назначение права. Правовые презумпции и принципы права - самостоятельные правовые явления, которые недопустимо смешивать. Принцип добросовестности участников гражданских правоотношений должен закрепляться в гражданском законодательстве не в качестве презумпции, а наряду с ней.

С одной стороны, принцип добросовестности адресован физическим и юридическим лицам, выступающим в качестве участников гражданских правоотношений и содержащий требование добросовестного поведения, а с другой - государству, которое должно действовать добросовестно, устанавливая «правила игры» для участников гражданском оборота и соблюдать установленные правила. Наличие же в гражданском законодательстве презумпции добросовестности предполагает, что указанные ор- 
DOI: 10.7256/1811-9018.2013.11.10033

При цитировании этой статьи сноска на dоі обязательна

\section{Право и политика $11(166) \cdot 2013$}

ганы должны исходить из ее положений при оценке поведения всех субъектов гражданско-правовых отношений, в том числе предпринимателей.

Следуя требованиям принципа добросовестности, законодатель не должен предоставлять защиту интересам недобросовестных участников гражданского оборота. Так, в соответствии с п. 1 ст. 314 ГК Беларуси и п.1 ст. 333 ГК России, суду предоставлено право снижать размер подлежащей взысканию неустойки. Однако следует принимать во внимание, что участники гражданских правоотношений свободны в установлении своих прав и обязанностей на основе договора, а также в принятии на себя предусмотренной законом или договором ответственности в отношении своего контрагента и в определении ее объема. При этом в соответствии со ст. 9 ГК Беларуси и ст. 10 ГК России добросовестность и разумность участников гражданского оборота предполагается. Безусловно, нельзя исключать того, что отдельные участники гражданского оборота, имеющие более сильные позиции на рынке, способны навязывать контрагентам свои условия в части размера договорной неустойки. Наличие в действующем законодательстве правила о снижении неустойки вызвано потребностью установить определенное равновесие сил в договорных отношениях, защитить «слабую» сторону договора.

Белорусский законодатель предоставляет суду право по своему усмотрению определять размер процентов, на который может быть снижена неустойка в отношении различных субъектов. Кроме того, в одних случаях суд удовлетворяет ходатайство стороны об уменьшении неустойки, а в других - нет, поскольку снижение неустойки является не обязанностью, а правом суда. Если же суд снижает подлежащую взысканию неустойку по собственной инициативе, то ограничивается и принцип равенства участников гражданских правоотношений. Но, что самое важное, снижая размер подлежащей взысканию неустойки, суд поощряет неисправного, а нередко и недобросовестного должника.

В контексте проводимого исследования вспоминается весьма точный тезис О.С. Иоффе: «всякий принцип, каким бы общим он ни был, не лишается своего значения и тогда, когда он терпит те или иные исключения, если, однако, последние действительно являются исключениями...» ${ }^{20}$. Поэтому каждый

${ }^{20}$ Иоффе О.С. Ответственность по советскому гражданскому праву. - Л., 1955, С. 29. раз при решении вопроса о допустимости тех или иных ограничений принципов гражданского права, законодателю необходимо, прежде всего, оценить, насколько они оправданы с точки зрения баланса частных и общественных интересов. А, во-вторых, строго следовать правилу о том, что любое ограничение принципа должно устанавливаться только на основании закона и в соответствии с Конституцией страны. Кроме того, полагаем, что корректировка отдельных положений ГК Беларуси путем рецепции положений ГК России будет способствовать унификации законодательства стран-участниц союзного государства в духе положений принятого ранее Модельного Гражданского кодекса стран СНГ.

\section{Библиография:}

1. Алексеев С.С. Проблемы теории права: курс лекций: в 2 т. - Свердловск: Свердл. юрид. ин-т, 1972. - Т. 1: Основные вопросы общей теории социалистического права. - 396 с.

2. Гаджиев Г.А. Конституционные принципы рыночной экономики : развитие основ гражданского права в решениях Конституционного Суда Российской Федерации. - М.: Юристъ, 2002. - 284 с.

3. Иоффе О.С. Ответственность по советскому гражданскому праву. - Ленингр. гос. ун-т. - Л., 1955. $-310 \mathrm{c}$.

4. Комиссарова Е. Г. Об основных началах гражданского законодательства С. 13-20 // Журнал российского права. - 2001. - № 5. - С. 13-20. 5. Кузнецова О.А. Принципы гражданского права: современное состояние вопроса // Власть закона. 2011. - № 4 (8). - С. 87-95.

5. Кузнецова О.А. Общепризнанные принципы и нормы международного права - часть правовой системы, права или законодательства? // Правовое государство: теория и практика. 2010. - № 2. - С. 42-47.

6. Лившиц Р.3. Современная теория права: крат. очерк; Рос. акад. наук, Ин-т государства и права. - М., 1992. - 93 с.

7. Матузов Н.И. Теория государства и права: учебник / Н.И. Матузов, А.В. Малько. - М.: Юристъ, 2003. -512 c.

8. Martijn W. Hesselink The general principles of civil law: their nature? Roles and legitimacy Режим доступа:// http://ssrn.com/abstract=1932146. - Дата доступа: 09.09.2013. 
DOI: 10.7256/1811-9018.2013.11.10033

При цитировании этой статьи сноска на doi обязательна

Человек и государство

\section{References (transliteration):}

1. Alekseev S.S. Problemy teorii prava: kurs lektsii: v 2 t. - Sverdlovsk: Sverdl. yurid. in-t, 1972. - T. 1: Osnovnye voprosy obshchei teorii sotsialisticheskogo prava. - $396 \mathrm{~s}$.

2. Gadzhiev G.A. Konstitutsionnye printsipy rynochnoi ekonomiki : razvitie osnov grazhdanskogo prava v resheniyakh Konstitutsionnogo Suda Rossiiskoi Federatsii. - M.: Yurist', 2002. - 284 s.

3. Ioffe O.S. Otvetstvennost' po sovetskomu grazhdanskomu pravu. - Leningr. gos. un-t. - L., 1955. - 310 s.

4. Komissarova E. G. Ob osnovnykh nachalakh grazhdanskogo zakonodatel'stva S. 13-20 // Zhurnal rossiiskogo prava. - 2001. - № 5. - S. 13-20.
5. Kuznetsova O.A. Printsipy grazhdanskogo prava: sovremennoe sostoyanie voprosa // Vlast' zakona. 2011. - № 4 (8). - S. 87-95.

6. Kuznetsova O.A. Obshchepriznannye printsipy i normy mezhdunarodnogo prava - chast' pravovoi sistemy, prava ili zakonodatel'stva? // Pravovoe gosudarstvo: teoriya i praktika. 2010. - № 2. - S. 42-47.

7. Livshits R.Z. Sovremennaya teoriya prava: krat. ocherk; Ros. akad. nauk, In-t gosudarstva i prava.-M., 1992.-93 s.

8. Matuzov N.I. Teoriya gosudarstva i prava: uchebnik / N.I. Matuzov, A.V. Mal'ko. - M.: Yurist', 2003. - 512 s.

9. Martijn W. Hesselink The general principles of civil law: their nature? Roles and legitimacy Rezhim dostupa:// http://ssrn.com/abstract=1932146. - Data dostupa: 09.09.2013. 